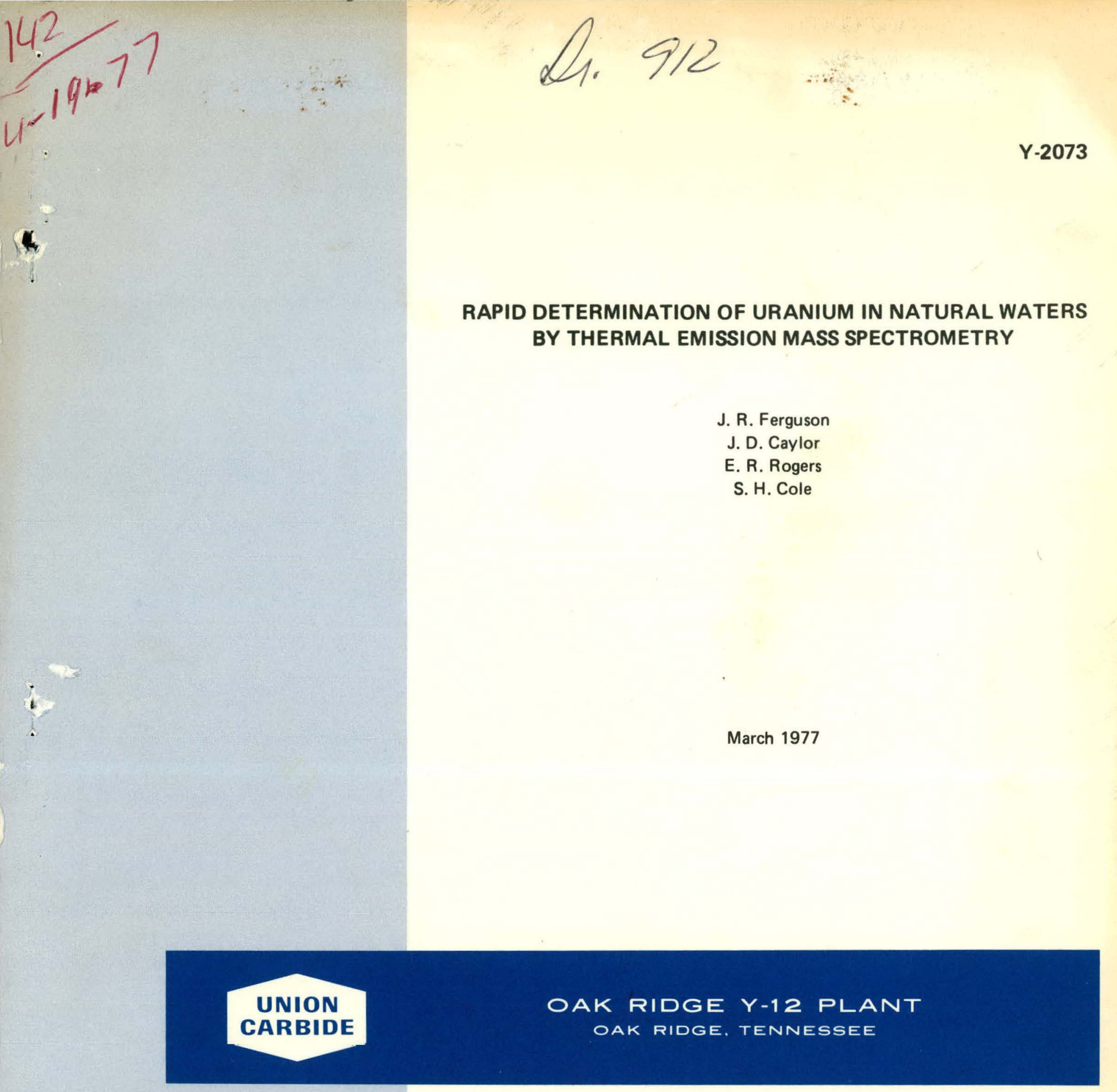

prepared for the U.S. ENERGY RESEARCH AND DEVELOPMENT ADMINISTRATION under U.S. GOVERNMENT Contract W-7405 eng 26 


\section{DISCLAIMER}

This report was prepared as an account of work sponsored by an agency of the United States Government. Neither the United States Government nor any agency Thereof, nor any of their employees, makes any warranty, express or implied, or assumes any legal liability or responsibility for the accuracy, completeness, or usefulness of any information, apparatus, product, or process disclosed, or represents that its use would not infringe privately owned rights. Reference herein to any specific commercial product, process, or service by trade name, trademark, manufacturer, or otherwise does not necessarily constitute or imply its endorsement, recommendation, or favoring by the United States Government or any agency thereof. The views and opinions of authors expressed herein do not necessarily state or reflect those of the United States Government or any agency thereof. 


\section{DISCLAIMER}

Portions of this document may be illegible in electronic image products. Images are produced from the best available original document. 
Printed in the United States of America. Available from

National Technical Information Service

U.S. Department of Commerce

5285 Port Royal Road, Springfield, Virginia 22161

Price: Printed Copy $\$ 3.50$; Microfiche $\$ 3.00$

This report was prepared as an account of work sponsored by the United States Government. Neither the United States nor the Energy Research and Development Administration, nor any of their employees, nor any of their contractors, subcontractors, or their employees, makes any warranty, express or implied, or assumes any legal liability or responsibility for the accuracy, completeness or usefulness of any information, apparatus, product or process disclosed, or represents that its use would not infringe privately owned rights. 


\title{
RAPID DETERMINATION OF URANIUM IN NATURAL WATERS BY THERMAL EMISSION MASS SPECTROMETRY
}

\author{
J. R. Ferguson \\ J. D. Caylor \\ E. R. Rogers \\ S. H. Cole
}

Y-12 Plant Laboratory

Product Certification Division

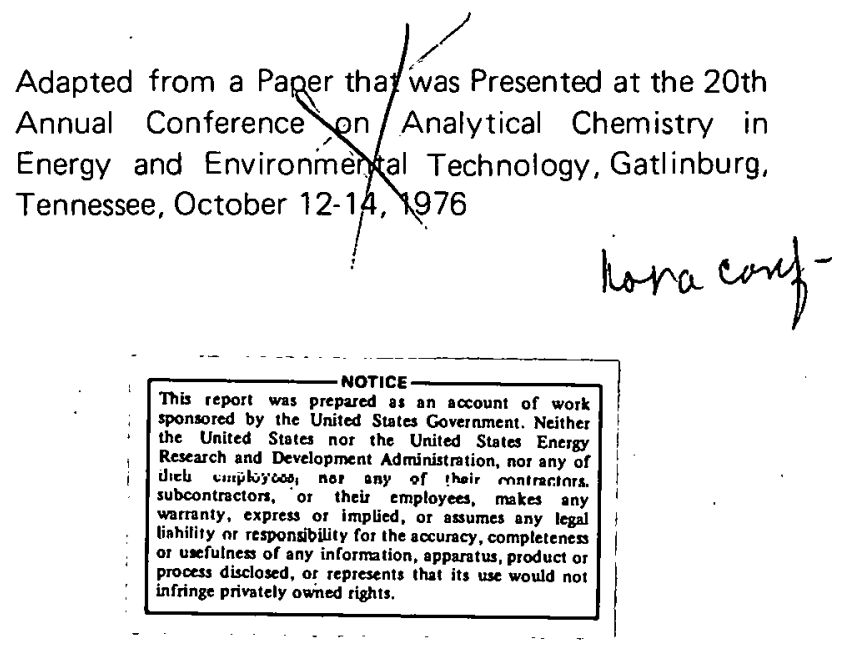

Oak Ridge Y-12 Plant

P. O. Box Y, Oak Ridge, Tennessee 37830

Prepared for the US Energy Research and Development Administration

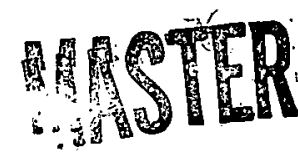

Under US Government Contract W-14ü5-eng-20 
ABSTRACT

A six-inch radius mass spectrometer has been constructed and demonstrated to adequately analyze water samples for uranium concentrations down to 5 to $10 \mathrm{ng} /$ liter (ppt). The precision and accuracy of the isotope-dilution, thermal emission method is sufficient to meet the needs of the Uranium Resources Evaluation (URE) project. A single analyst can analyze in excess of 50 samples per day, including all preparation and instrument time. This analysis rate will meet the economic constraints of the URE analytical program. 
CONTENTS

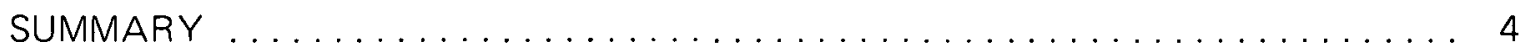

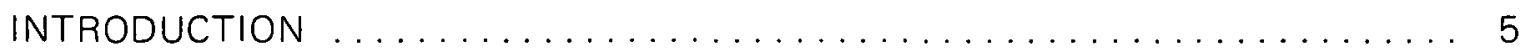

DETERMINING URANIUM IN NATURAL WATERS $\ldots \ldots \ldots \ldots \ldots \ldots \ldots$

Experimental Method .................................... 6

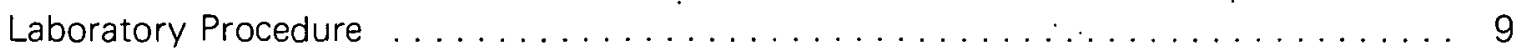

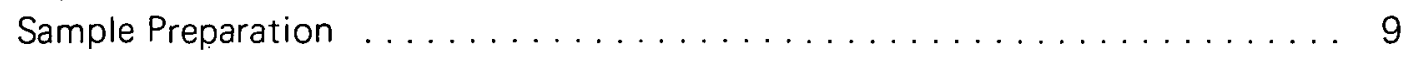

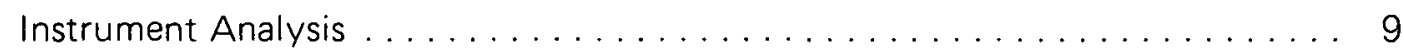

Results ................................... 10

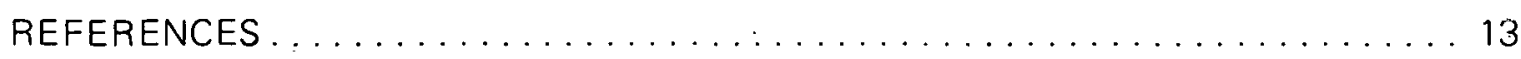




\section{SUMMARY}

A method has been developed to rapidly analyze natural water samples for part-per-trillion (ng/l) concentrations of uranium using a custom-built thermal-emission mass spectrometer.

The filtered water sample is spiked with ${ }^{233} U$ as an internal standard and extracted with a $2 \%$ solution of TOPO (trioctylphosphine oxide) in carbon tetrachloride. An aliquot of the organic phase is evaporated and the uranium in the residue extracted with aqueous ammonium carbonate. A $5-\mu$ aliquot is taken and dried on a flat rhenium ribbon filament and inserted into the mass spectrometer.

A uranium concentration of $3 \mathrm{ng} / \mathrm{l}$ will yield a count rate greater than three times the standard deviation, plus the mean of the background, and is defined as the lowest determinable concentration. The standard deviation of the method is $3 \%$ at $800 \mathrm{ng} / \mathrm{l}, 16 \%$ at $8 \mathrm{ng} / \mathrm{l}$, and $20 \%$ at $5 \mathrm{ng} / \mathrm{l}$. The accuracy of the method has been evaluated by comparing the results with a fluorescence procedure. There is very gond agreement for water samples with uranium concentrations from 200 to $1000 \mathrm{ng} / \mathrm{l}$.

The mass spectrometer is a 6-inch-radius, 6n-degree-secter inctrumont equipped for ion counting and having a vacuum system allowing rapid sample changing while maintaining a high source vacuum. A multiplexer and high-voltage switch provide synchronized peak switching and scaler gating for monitoring three isotopes of uranium 238, 235, and 233. With this instrument, an analyst can achieve an analysis rate in excess of 50 samples per eight-hour shift. 


\section{INTRODUCTION}

The hydrogeochemical survey being conducted by the UCC-ND Uranium Resource Evaluation (URE) project requires the analysis of large numbers of surface and ground water samples for $<\mathrm{mg} / \mathrm{l}(\mathrm{ppm})$ concentrations of dissolved uranium. Uranium concentrations in natural waters vary from $<10 \mathrm{ng} / \mathrm{l}(\mathrm{ppt})$ to $>1 \mathrm{mg} / \mathrm{l}(\mathrm{ppm})$. An analytical method with sufficient precision, accuracy, and sensitivity was needed to analyze samples containing uranium at less than the $0.2 \mu \mathrm{g} / \mathrm{l}(\mathrm{ppb})$ concentration limit determinable by fluorescence spectroscopy. Additionally, the method used must be capable of analyzing 30 to 50 samples per day to be cost effective in completing the tens of thousands of water samples expected to be received.

Isotope-dilution, thermal emission (IDTE) mass spectrometry was selected by laboratory personnel at the Oak Ridge Y-12 Plant(a) as the analytical method to be used to meet these needs. High-resolution mass spectrometry with ion-counting detection has been used successfully in determining both the isotopic and total concentration of uranium in water, but sample analysis rates are usually no more than a few samples per day.

To avoid a large capital expenditure for a high-resolution instrument, a six-inch-radius mass spectrometer was modified to meet these analytical needs. Extensive electronic and mechanical fabrication was required before the low-resolution instrument could be used to analyze for $\mathrm{ng} / \mathrm{l}$ (ppt) quantities of uranium with a rate of 30 to 50 samples per day.

Adequate sensitivity was achieved by operating the mass spectrometer with an ion-counting detector using a commercial preamplifier, an amplifier/discriminator, a ratemeter, and photon counters. In-house designed and fabricated multiplexing and peak-switching circuitry was used in gating the scalers in synchronization with peak stepping on the the accelerating voltage. A diffusion pump was added to the airlock pumping system to increase the speed of sample throughput and reduce source maintenance problems. The need for a large analysis rate and a minimum of maintenance is very important to the URE analytical program because of the large number of samples to be processed and the necessity of maintaining a constant sample flow through the laboratory.

(a) Operated by the Union Carbide Corporation's Nuclear Division for the US Enlergy Research and Development Administration. 


\section{DETERMINING URANIUM IN NATURAL WATERS}

\section{EXPERIMENTAL METHOD}

The mass spectrometer that was modified for use in the URE program was originally intended to be a replacement for a 1950-vintage, six-inch-radius mass spectrometer used for uranium isotopic analysis in the $\mathrm{Y}-12$ Plant Laboratory. A view of the mass spectrometer, with the complete modifications, is presented in Figure 1. The instrument

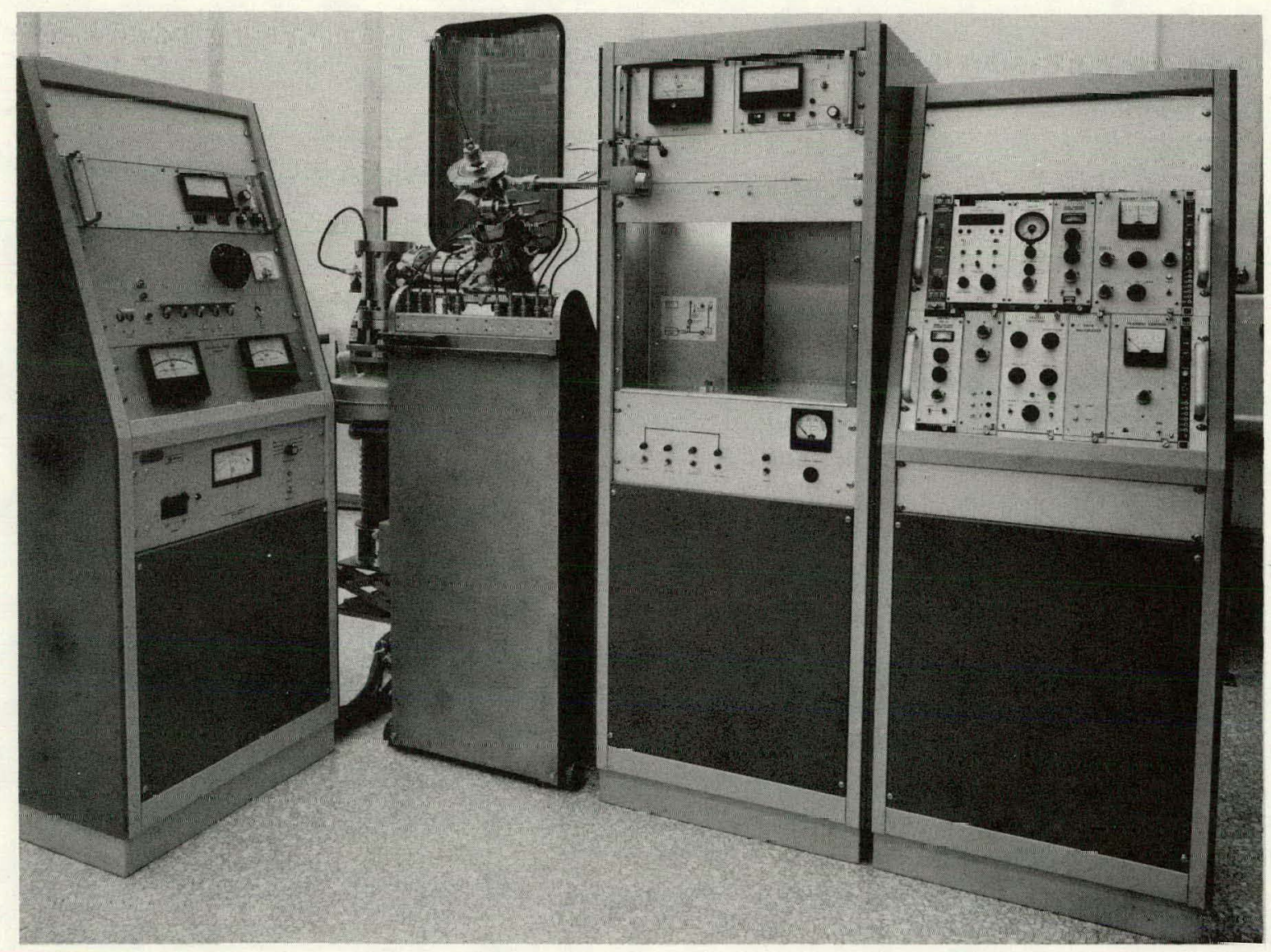

Figure 1. ISOTOPE-DILUTION, THERMAL EMISSION MASS SPECTROMETER.

164621

has a 6-inch-radius, 60-degree-sector, differentially pumped andyzer empluying a Nier-type source modified for thermal ionization. 1 The standard vacuum-lock entry system ${ }^{2}$ was modified by the addition of a diffusion pump to the vacuum-lock pumping system. This change was made to increase sample throughput by minimizing the pump-down time, to minimize source contamination, and to reduce the time required for source changing. Additionally, the lower pressure reached in the vacuum lock before opening the source valve reduces the loading on the cryogenic trap. This improvement allows the source pumping system to maintain maximum operating efficiency. Maximum sample throughput can thus be maintained for several months without vacuum system maintenance. 
When the adjustable receiver slit is set at the point where flat top peaks are just achieved, the resolution of the mass spectrometer is approximately 400 at $10 \%$ valley. However, for this application the receiver slit. is widened to slightly greater than $100 \%$ of the beam. width to minimize the possibility of errors caused by peak jumping with the accelerating voltage. Resolution may be sacrificed in this way because interferences from the masses adjacent to 233, 235, and 238 are not observed in these samples. This lack of interference is expected, following double extraction of the sample and early removal of any residual organics on the filament before the uranium ionization temperatures are reached. The abundance sensitivity under these conditions is a modest, but acceptable, 3000 .

The analyzer region is maintained at $<1 \times 10^{-8}$ torr $\left(<1.3 \times 10^{-6} \mathrm{~Pa}\right)$ with an ion pump, and no pressure change is observed in this region during routine sample analysis. The source region, which is pumped with an oil diffusion pump, reached $3 \times 10^{-8}$ torr $\left(4 \times 10^{-6} \mathrm{~Pa}\right)$ during quiescent periods and fluctuates between $5 \times 10^{-7}$ and $3 \times$ $10^{-5}$ torr $\left(6.7 \times 10^{-5}\right.$ and $\left.4 \times 10^{-3} \mathrm{~Pa}\right)$ during analysis. The high pressure of $3 \times x$ $10^{-5}$ torr $\left(4 \times 10^{-3} \mathrm{~Pa}\right)$ is reached while the source is open to the vacuum lock and drops instantly to $<5 \times 10^{-6}$ torr $\left(<6.7 \times 10^{-4} \mathrm{~Pa}\right)$ when the source flapper valve is closed.

A block diagram of the data system, including a timing diagram of the multiplexing and demultiplexing signals, is given in Figure 2. The heart of the:system is the block labeled

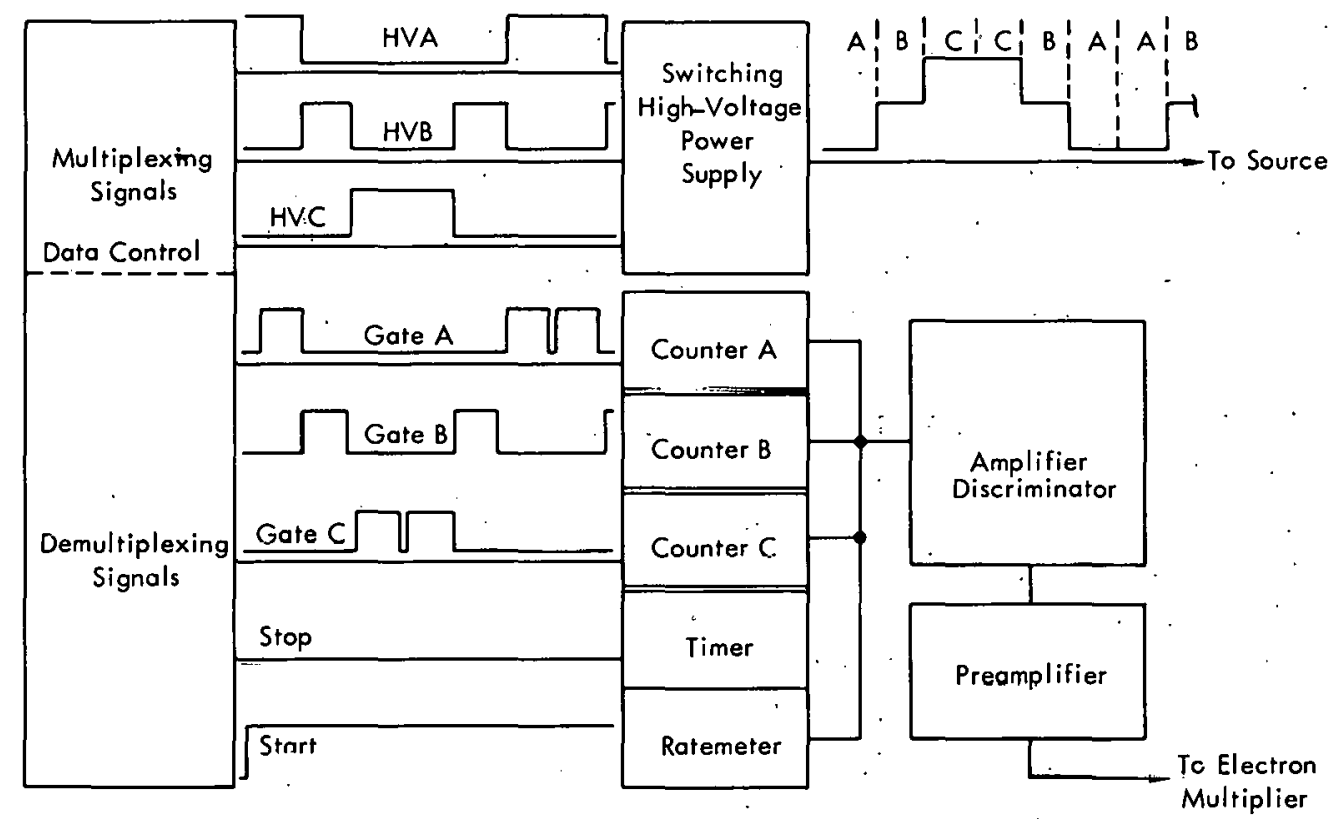

Figure 2. PRINCIPAL COMPONENTS OF THE MASS SPECTROMETER ELECTRONICS.

"data control". All of the multiplexing and demultiplexing signals are generated within. this unit. 
The waveforms labeled "HVA", "HVB", and "HVC" are the synchronous signals used to switch the high-voltage power supply. These signals are at transistor transistor logic (TTL) levels and are optically coupled into the high-voltage supply. Solid-state relays are used to achieve the high-speed peak switching. The output of the high-voltage supply is a stairstepping waveform, as shown in the upper right corner of the diagram. Due to the changing intensity of the ion beam, the high voltage is switched in a triangular manner. This arrangement helps to average the peak-intensity variations. During the time period labeled " $A$ ", the positive beam of $233 \mathrm{U}$ atoms is striking the first dynode of the electron multiplier to generate output current pulses of 5 to 10-nanosecond duration. These pulses are fed into a high-speed, low-input impedance preamplifier which converts the current into useable voltage pulses.

The nutput of the promplifier is applied to the input of the main amplifier and discriminator module. This unit provides a voltage gain as well as a baseline discriminator control. The output of the main amplifier is applied th a ratemeter and lhree counters labeled " $A$ ", " $B$ ", and " $C$ ". The ratemeter is used as an analog device when adjusting the high-voltage controls to maximize the ion-beam intensity of each of the three masses.

The labeled counters are photon counters that will accept negative pulses at a rate of $200 \mathrm{MHz}$. The counters are gated in synchronization with the appropriate ion beam that is being switched at a rate of approximately 10 times per second. The gate signals have a 2-msec delay from the time the high voltage is switched to allow the ion beam to reach constant intensity. Each of the counters has a capacity of $10^{7}-1$ counts. The data appear on a light-emitting diode (LED) front-panel display as well as a rcar-panel outpul cunnector for use with data storage equipment.

A preset timer is used to produce a stop signal at the end of the counting period. This stop signal is rouled to the data control unit. The control unit senses the stup signal, bul continues the scan until it reaches the end of a complete cycle. This ter.hnique assuras that each of the three peaks is counted for an identical number of cycles.

After the total counts from the three isotopes have been acquired, the $\mu \mathrm{g} / \mathrm{l}(\mathrm{ppb})$ $238 \mathrm{U}$ content is calculated, using Equation 1 (Figure 3). In this equation, the $238 \cup$ correction factor (CF) is the mass discrimination correction for 1. $\mu \mathrm{g} \mathrm{U} / \mathrm{I}=\frac{{ }^{238} \mathrm{U} \text { Counts }}{233 \mathrm{U} \text { Counts }} \times 0.5 \times{ }^{238} \mathrm{UCF}$ $238 \mathrm{U}$ rclative to the $233 \mathrm{U}$ determıned at the beginning of each shift. This multiplier is approximately 1.1. Calculations by this method are accurate in the concentration range from 0.005 to $5.0 \mu \mathrm{g} / \mathrm{l}(\mathrm{ppb})$. At higher concentration

2. $\mu \mathrm{g} \mathrm{U} / \mathrm{I}=\frac{{ }^{235} \mathrm{U} \text { Counts }}{233 \mathrm{U} \text { Counts }} \times 0.5 \times 141.8^{235} \mathrm{U} \mathrm{CF}$ Figure 3. EQUATIONS USED TO GALCULATE TOTAL URANIUM CONCENTRATION.

levels, the extremely high $238 \mathrm{U}$ count rate requires using the $235 \mathrm{U} / 233 \mathrm{U}$ ratio, as indicated by Equation 2 (Figure 3). The $235 \mathrm{U} C F$ is the $235 \mathrm{U} / 233 \mathrm{U}$ massdiscrimination CF, and is approximately 1.05 . 


\section{LABORATORY PROCEDURE}

\section{Sample Preparation}

Sample preparation involves pipeting $10 \mathrm{ml}$ of the filtered water sample into a $50-\mathrm{ml}$ disposable centrifuge cone. The sample is then made to a concentration of $0.5 \mu \mathrm{g} / \mathrm{l}$ in $233 \mathrm{U}$ by adding $5 \mu \mathrm{l}$ of a $1 \mathrm{mg} / \mathrm{l} 233 \mathrm{U}$ stock solution. One hundred microliters of concentrated nitric acid are added, followed by one milliliter of a $2 \%$ solution of trioctylphosphine oxide (TOPO) dissolved in carbon tetrachloride. When a batch of 30 samples has been prepared to this point, the centrifuged cones are put in a mechanical shaker and the two phases equilibrated for five minutes. After the phases separate, the upper (aqueous) portion is then drawn off, with the aid of a vacuum water trap apparalus, and discarded. The cap is loosely reapplied to both the centrifuge cone and the samples, then the samples are set aside to allow the carbon tetrachloride to evaporate. After the carbon tetrachloride has evaporated, the samples may be stored until there is a convenient time for analysis on the mass spectrometer.

The samples are left in the dried TOPO until the mass spectrometer operating conditions have been established and standardized to determine the mass discrimination factors. Two hundred microliters of saturated ammonium carbonate solution are then added to the centrifuge cone containing the residual TOPO. The cones are then heated over a hot plate unitil the TOPO melts. Care must be exercised to avoid overheating the mixture. The heated mixture is then swirled in the bottom of the cone to aid in the back extraction of the uranium into the ammonium carbonate solution. An aliquot of this solution is to be loaded onto the filament for analysis.

The filaments used are the flat-ribbon type, fabricated from zone-refined rhenium and mounted on $\mathrm{V}$-block mounts. The filaments have been preconditioned by heating at five amperes in a vacuum chamber for one hour with a $1 \times 10^{-5}$ torr $\left(1.33 \times 10^{-3} \mathrm{~Pa}\right)$ partial pressure of benzene vapor present for carbonization.3,4 After preconditioning, the fillaments are chccked in the mass sper.trnmeter for cleanliness and uranium contamination. The filaments are reused for 30 to 50 analyses before being retipped. This maintenance schedule saves between two and three dollars per sample in labor and material costs. The filament requires only a brief decontamination step of 10 to 15 seconds after the analysis of each sample.

\section{Instrument Arialysis}

A five-microliter aliquot of the ammonium carbonate solution containing the uranium extracted from the first sample is pipeted onto the filament and evaporated to dryness by passing a 100-milliampere current through the filament. The best uranium count rates are achieved if the solution is dried slowly over a one to two-minute period. .

When the ammonium carbonate solution is evaporated, the filament is threaded onto the extractor rod and loaded into the vacuum lock. While the vacuum lock is being pumped, 
the next sample is pipeted onto another filament and the evaporation of the ammonium carbonate is begun. By this method of sample handling, the evaporation time of the sample does not contribute significantly to the analysis costs. When the pressure in the vacuum lock reaches $5 \times 10^{-5}$ torr $\left(6.7 \times 10^{-3} \mathrm{~Pa}\right)$ or less, the vacuum lock is isolated from its pumping system and the source flapper valve is opened to allow placement of the filament block into position. When the filament block is securely in place, the extractor rod is withdrawn into the vacuum lock and the source flapper valve closed. The source pressure will drop instantly to less than $5 \times 10^{-6}$ torr $\left(6.7 \times 10^{-4} \mathrm{~Pa}\right)$. Benzene vapor is bled in through a Granville-Phillips metering valve until a source pressure of $2 \times$ $10^{-6}$ torr $\left(2.7 \times 10^{-4} \mathrm{~Pa}\right)$ is maintained. This source of carbon, in addition to that provided by precarbonization of the filament, aids in reducing the uranium oxide to the metal.

The filament power is raised slowly to avoid any large pressure rises dise to outgassing nf the lildrueril. When the $233 \mathrm{U}$ peak indicates a count rate from 100 and 1000 counts per second on the ratemeter, the analyst presses the "start" button to initiate the counting cycle. At this point, the filament power meter should read between eight and ten watts. The analyst continues to raise the tilament power while observing the $10^{5}$ digit of the $238 \mathrm{U}$ channel. By estimating the rate of change of the $10^{5}$ digit, the $238 \mathrm{U}$ count rotc is kept at a maximum without exceeding $5 \times 10^{5}$ counts per second, or sixteen watts of filament power. Keeping the count rate below $5 \times 10^{5}$ counts per second serves to minimize coincidence losses. At higher concentrations it becomes increasingly difficult to keep the $235 \mathrm{U}$ ratc below $5 \times 10^{5}$ courits per second. If a sample is found to contain greater than $5 \mathrm{ppb}$ uranium, the filament power is increased rapidly from 8 to 16 watts and the $235 U / 233 U$ ratio is used to determine the uranium concentration. When the 30-second counting interval has ended, the filament power control is raised to full scale to decontaminate the filament. While decontamination is taking place, the analyst calculates the sample concentration in parts per billion of $238 \mathrm{U}$. The filament power is then reduced to 16 watts and a short count taken to assure that there is no uranium remaining on the filament. The filament power is then reduced to the minimum value and the analysis of the next sample started. Thirty samples appears to be the optimum batch size, as some difficulties in pipeting the sample onto the filament arises if too lengthy a time elapses between back extraction intn the ammonium carbonate and loading of the sample onto the filament.

\section{RESULTS}

Development of this procedure was completed in May 1976; and, during May and June. standard and control samples were analyzed to establish the precision and accuracy limits. These results are summarized in Table 1. Of particular significance in these data is the value of the blank (or uranium background level in the clean-room laboratory), the standard deviation of the blank value, and the effect of these on the accuracy and precision at the various concentration levels. The uranium background level in the clean-room laboratory, scheduled to be located in the Y-12 Plant, is enriched in $235 \mathrm{U}$. For this reason, the $238 \mathrm{U} / 235 \mathrm{U}$ ratio is monitored on all samples. If this ratio falls below 
Table 1

DAY-TO-DAY PRECISION AND ACCURACY OF ANALYZING WATER STANDARDS BY ISOTOPE DILUTION-THERMAL EMISSION MASS SPECTROMETRY

\begin{tabular}{|c|c|c|c|c|c|}
\hline \multicolumn{2}{|c|}{ Concentration (ppb) } & \multirow{2}{*}{$\begin{array}{c}\text { Corrected } \\
\text { for } \\
\text { Blank }\end{array}$} & \multirow{2}{*}{$\begin{array}{l}\text { Standard } \\
\text { Deviation }\end{array}$} & \multirow{2}{*}{$\begin{array}{c}\text { Percent of } \\
\text { Standard } \\
\text { Deviation }\end{array}$} & \multirow{2}{*}{$\begin{array}{c}\text { Number of } \\
\text { Samples per } \\
\text { Location }\end{array}$} \\
\hline Standard & Uncorrected & & & & \\
\hline 0.800 & 0.827 & 0.826 & 0.028 & 3.4 & 12 \\
\hline 0.080 & 0.087 & 0.086 & 0.0038 & 4.4 & 12 \\
\hline 0.008 & 0.009 & 0.008 & 0.0014 & 15.6 & 10 \\
\hline 0.005 & 0.006 & 0.005 & 0.0011 & 18.3 & 8 \\
\hline Blank & 0.0013 & - & 0.0005 & 38.5 & 11 \\
\hline
\end{tabular}

10, this result is taken as an indication of sample contamination and the particular sample must be reanalyzed. The lower reporting limit is determined by the contamination level rather than by a lack of instrument sensitivity.

The laboratory was closed for remodeling at the end of June before the pilot survey sampling team reached the northern section of the East Tennessee area. Fortunately, some prepilot survey sampling was completed in Michigan, Wisconsin, and Minnesota. This work provided a typical cross section of some 200 water samples from an area where the uranium concentration is expected to be extremely low. Results of analyzing these samples are reported in Table 2. The uranium concentrations are seen to fall

Table 2

GROUND AND SURFACE WATER SAMPLES FROM MICHIGAN, MINNESOTA, AND WISCONSIN ANALYZED BY ISOTOPE DILUTION-THERMAL EMISSION MASS SPECTROMETRY (Samples from Different Locations Given Different Treatments)

\begin{tabular}{ccccc}
\hline $\begin{array}{c}\text { Sample } \\
\text { ID }\end{array}$ & $\begin{array}{c}\text { Uranium } \\
\text { Concentration } \\
(\mu \mathrm{g} / \mathrm{l})\end{array}$ & $\begin{array}{c}\text { Standard } \\
\text { Deviation }\end{array}$ & $\begin{array}{c}\text { Percent of } \\
\text { Standard } \\
\text { Deviation }\end{array}$ & $\begin{array}{c}\text { Number of } \\
\text { Samples per } \\
\text { Location }\end{array}$ \\
\hline $330-345$ & 0.18 & 0.016 & 9.1 & 14 \\
$367-480$ & 0.17 & 0.013 & 7.8 & 14 \\
$421-434$ & 0.14 & 0.010 & 7.1 & 14 \\
$516-519$ & 0.09 & 0.015 & 17.0 & 4 \\
$300-311$ & 0.05 & 0.014 & 29.2 & 12 \\
$314-327$ & 0.03 & 0.007 & 21.9 & 14 \\
367.379 & 0.025 & 0.009 & 36.0 & 13 \\
$405-417$ & 0.018 & 0.010 & 55.6 & 13 \\
$382-385$ & 0.013 & 0.003 & 23.1 & 4 \\
$512-515$ & 0.009 & 0.005 & 55.6 & 4 \\
\hline
\end{tabular}

between 0.005 and $0.2 \mu \mathrm{g} / \mathrm{l}(\mathrm{ppb})$. Below $0.1 \mu \mathrm{g} / \mathrm{l}$, there is no real trend in the relative standard deviation (RSD) versus concentration. However, the RSD is significantly larger than on the controls of a similar concentration.

The samples in Table 2 from a given location were subjected to various treatments at the time of collection in an effort to determine the most meaningful means of collection and preservation. These treatments included: filtering with acidification, not 
filtering with acidification, filtering with no acidification, and not filtering with no acidification. An increase in the RSD, compared to thc standards, is undoubtedly a result of the various sample treatments. Further examination of the data in Table 2 indicates that IDTE mass spectrometry can analyze water samples for uranium at the 10 to $200-n g / l$ (ppt) concentration with good precision.

Data in Table 3 are from the analyses of samples from five different sites containing nearly identical uranium concentrations. These samples were treated, as previously

Table 3

GROUND AND SIJRFACE WATFA SAMPLEE FFOM MICHIGAN, MINNESOTA, AND WISCONSIN ANALYZED BY ISOTOPE DILUTION-THERIMAL EMISSION MASS SPECTROMETRY (Samples from Five Different Sites)

\begin{tabular}{ccccc}
$\begin{array}{c}\text { Sample } \\
\text { ID }\end{array}$ & $\begin{array}{c}\text { Uranium } \\
\text { Concentration } \\
(\mu \mathrm{g} / \mathrm{l})\end{array}$ & $\begin{array}{c}\text { Standard } \\
\text { Deviation }\end{array}$ & $\begin{array}{c}\text { Percent of } \\
\text { Standard } \\
\text { Deviation }\end{array}$ & $\begin{array}{c}\text { Number of } \\
\text { Samples per } \\
\text { Location }\end{array}$ \\
\hline $520-533$ & 0.37 & 0.005 & 1.4 & 4 \\
$35 n 353$ & 0.42 & 0.020 & 4.8 & 14 \\
452.465 & 0.42 & 0.020 & 4.8 & 14 \\
$401-404$ & 0.38 & 0.050 & 13.2 & 4 \\
$497-510$ & 0.42 & 0.080 & 18.6 & 14 \\
\hline
\end{tabular}

described, at the time of collection. An examination of these data indic.ates that these samples are distinctly different in behavior toward treatment at collection. Samples from the five locations show standard deviations ranging frnm 0.005 to $0.080 \mu \mathrm{g} / \mathrm{l}(\mathrm{ppb})$.

Water samples received from Texas often contain uranium at concentrotions $>0.2 \mu \mathrm{g} / \mathrm{l}(\mathrm{ppb})$, when analyzed by fluorescence spectroscopy. Several samples from inls area have been analyzed both by fluorescence and by IDTE mass spectrometry. In Figure 4 the uranium concentration found by mass spectrometry is plotted as a function of the concentration determined

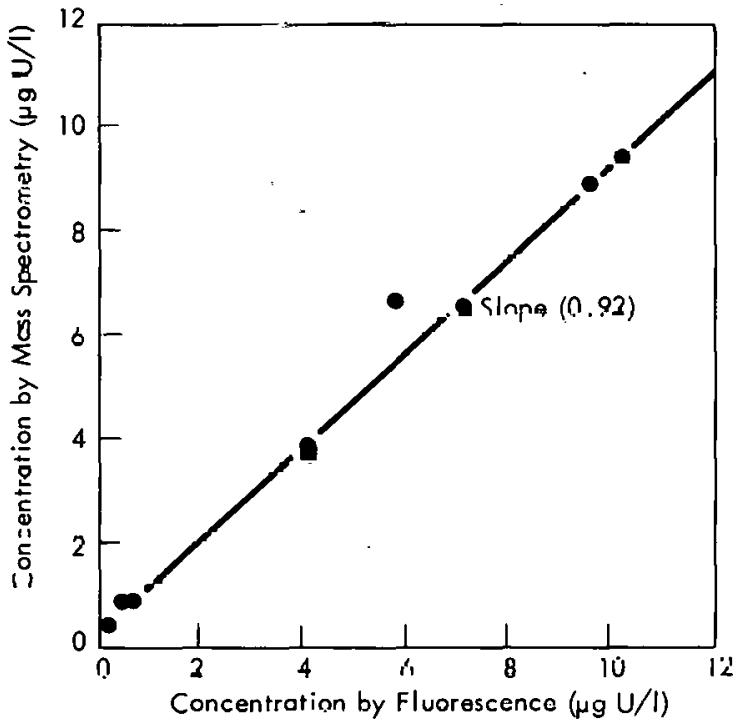

Figure 4. ANALYSIS OF WATER SAMPLES FOR URANIUM BY TWO ANAIYYTICAL METHODS. by fluorescence. The slope of 0.92 indicates that there is no operationally significant bias between the two melhods. As the URE program progresses, an ongoing comparison of the two methods will be made. 


\section{REFERENCES}

1. Sladky, R. E.; A Mass Spectrometer Surface Ionization Source for Use With a Vacuum Lock, Y-1173; Union Carbide Corporation-Nuclear Division, Oak Ridge Y-12 Plant, Oak Ridge, Tennessee; September 18, 1957.

2. Fultz, C. R. and Wilson, L. V.; A Metal Vacuum Lock for a Mass Spectrometer, Y-990; Union Carbide Corporation-Nuclear Division, Oak Ridge Y-12 Plant, Oak Ridge, Tennessee; April 21, 1953.

3. McHugh, J. A.; Int J Mass Spectrum Ion Physics, 3, pp 267 - 276 (1969).

4. Studier, M. H., Sloth, E. N., and Moore, L. P.; The Chemistry of Uranium in Surface Ionization Sources, 66, pp 133 and 134; January 1962. 


\section{Distribution}

Bendix Field Engineering -

Oak Ridge National Laboratory

Grand Junction

Carter, J. A.

Steinborn, $T$.

Shults, W. D.

Walker, R. C.

Energy Research and Development

Administration-Ames Laboratory

Oak Ridge Y-12 Plant

D'Silva, A.

Fassel, V. A.

Bernander, N. K.

Briscoe, O. W.

Burditt, R. B.

Cole, S. H. (5)

Energy Research and Development

Duggan, H. G.

Administration - Grand Junction

Boyer, B.

Grutt, E. W., Jr

Malan, R. C.

Roach, C. H.

Shannon, S.

Energy Research and Development

Administration - Oak Ridge

Butts, D. D.

Hickman, H. D.

Leed, R. E.

Scott, T. H.

Zachry, D. S., Jr

Lawrence Livermore Laboratory

Tinney, J. F.

Los Alamos Scientifie: I Ahnratory

Abernąthy, R. M.

Sharp, R. R.

Fèrguson, J. R. (5)

Fraser, R. J.

Futrell, T. L.

Jones, F. W.

Kahl, K. G.

Keith, A.

Kite, H. T.

Martin, W. R./Googin, J. M.

Mason, D. L

McBryde, W. T.

McLendon, J. D

Morrow, R. W. (5)

Phillips, L. R.

Rhew, J. E.

hogers, E. R. (5)

Schreyer, J. M.

Smith, H. F., Jr

Smith, R. D.

Tewes, W, E.

White, J. C.

Y-12 Cientral Files (master copy)

$Y$-12 Central Files (route copy)

$Y-12$ Central Files ( $Y-12 R C)$

$Y-12$ Central Files (25)

Arendt, J. W

Butz, T, R.

Paducan Gàseous Diffusion Plant

ragle, S. W.

Bewley, H. D.

Levin, R. W.

Nichols, C. E.

Sáváiulah Rlver Laboratơry

Stief, S. S.

Weber, C. W.

Folger, R. L.

Wilcox, W. J., Jr

In addition, this report is distributed in accordance with the category UC-51, Nuclear Raw Materials, as given in the USERDA Standard Distribution Lists for Unclassified Scientific and Technical Reports, TID-4500. 